\title{
URGENSI KETELADANAN DALAM KELUARGA (Sebuah Refleksi Dakwah Rasulullah pada Keluarganya)
}

\author{
Akhirudin \\ Fakultas Agama Islam Universitas Islam Attahiriyah \\ JIn. Melayu Kecil III No.15 RT.5/ RW 9 Bukit Duri, Tebet, Jakarta Selatan 12840 \\ Email : akhirudindc@gmail.com
}

\begin{abstract}
:
The Importance of Exemplary in the Family. Islamic education in the family is a process of forming Islamic personality in children. The role and duty of parents as primary educators to give good education for their children is essential. Furthermore, role modeling is one of most powerful tools to influence children characteristics. However, parents as the first-generation educators have not yet been fully perceived for the majority of Muslim families today. Therefore, it is very important to re-optimize the role of parents in the family to avoid crisis in role modeling. This article discusses about Role Modeling in the Family that has been exemplified by Rasulullah SAW in his da'wah to his kin and families. Role modeling in education is the most effective method/tool to prepare children in terms of morals (Akhlaq), psychology, and social. The role modeling that should be taught includes aspects of worship, Sharia (Islamic law), and Akhlaq. As it has been exemplified by Prophet Muhammad SAW in the education. First, educators show honesty. Second, educators must show fairness to their children as a good role model. Third, educators must show affection to their children. Fourth, educators should have a gentle attitude and hold on to Islamic Manhaj in their everyday behavior. Parents as primary educators should give a good example by teaching and implementing the teachings of Rasulullah SAW and the godliness of his companions as the best role models of all the time.
\end{abstract}

Keywords: Role Modeling in the Family, Reflections on the Da'wah of Rasulullah.

Abstract: Urgensi Keteladanan dalam Keluarga. Pendidikan Islam dalam keluarga merupakan proses pembentukan kepribadian Islam pada anak. Diperlukan peran dan tanggung jawab orang tua sebagai pendidik utama dalam mendidik anak dengan baik. Selain itu, adanya keteladanan pendidik merupakan salah satu cara berpengaruh dalam pada diri anak. Orang tua adalah sebagai pendidik pertama generasi, namun belum dirasakan sepenuhnya bagi mayoritas keluarga Muslim saat ini. Oleh karena itu, sangat penting untuk mengoptimalkan kembali peran orang tua dalam keluarga agar tidak terjadi krisis keteladanan. Tulisan ini mengupas tentang Keteladanan dalam Keluarga yang telah dicontohkan Rasulullah SAWpada saat dakwah menyeruh kaum kerabat. Pada akhirnya keteladanan dalam pendidikan adalah metode/ cara yang efektif dalam mempersiapkan anak dari segi Akhlak, mental dan sosial. Keteladanan yang diajarkan meliputi aspek ibadah, syariat dan akhlak. Hal ini telah dicontohkan Nabi Muhammad SAWdalam mendidik. Pertama, pendidik menunjukkan kejujuran. Kedua, pendidik harus menunjukkan keadilan kepada anak sebagai teladan yang baik. Ketiga, pendidik harus menunjukkan kasih sayang kepada anak. Keempat, pendidik memiliki sikap lemah lembut dan berpegang pada manhaj Islam dalam beretika sehari-hari. Orang tua sebagai pendidik pertama harus memberikan keteladanan dengan mengajarkan sekaligus mengamalkan ajaran Rasulullah SAWdan kesalihan para sahabat sebagai peletak keteladanan terbaik sepanjang masa.

Kata Kunci: Keteladanan dalam Keluarga, Refleksi Dakwah Rasulullah 


\section{Pendahuluan}

Kitab suci al-Qur'an menyatakan bahwa dalam diri Rasulullah SAWterdapat suri tauladan yang baik (uswatun hasanah) bagi umat manusia. Hal ini difirmankan oleh Allah dalam surat al-Ahzab: 21

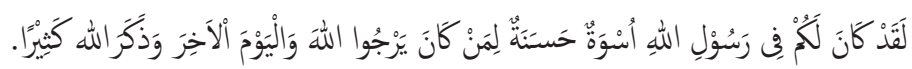

Sesungguhnya pada (diri) Rasulullah itu (terdapat) suri tauladan yang baik bagi orang yang mengharap (keridhaan) Allah dan Hari Akhirat serta banyak mengingat Allah.

Sebagai uswatun hasanah (suri tauladan yang baik), seluruh tindakan dan langkah-langkah yang dilakukan oleh Rasulullah Saw. menjadi sumber legitimasi atas perbuatan dan tindakan dalam seluruh aspek kehidupan umat Islam. Bahkan pada tingkat tertentu, berbagai praktek ajaran agama menyangkut ritual ibadah, yang dilaksanakan oleh seorang muslim, tidak boleh menyimpang dari apa yang telah dicontohkan oleh Rasulullah Saw. tersebut.

Itulah sebabnya apa yang dilakukan oleh Rasulullah SAWmenjadi dasar pijakan bagi seorang muslim, dalam setiap tindakan dan perbuatannya. Yakni perbuatan yang bersangkut paut dengan segala sesuatu yang mengandung muatan keagamaan. Hal ini juga berlaku bagi kehidupan seorang dai dalam kegiatan dakwahnya. Karena berdakwah pada hakekatnya adalah tindakan penyampaian informasi yang mengandung muatan keagamaan kepada masyarakat luas.

Sejalan dengan itu, di kalangan pakar ilmu dakwah lazim diketahui, bahwa dalam kode etik dakwah Islam, ada kewajiban moral yang harus diindahkan oleh seorang dai ketika ia hendak melaksanakan aktivitas dakwahnya. Kode etik itu adalah, "bila seorang juru dakwah hendak melaksanakan dakwahnya di tengah-tengah masyarakat, terlebih dahulu ia harus melaksanakan dakwah itu bagi keluarganya sendiri". Tidak boleh terjadi, atau dipandang menyimpang dari etika dakwah, bila seorang dai tidak mampu mengajak keluarganya yang sudah seiman dengan dia, sementara dia sendiri sibuk mengajak orang lain dalam kegiatan dakwahnya. 
Tidak pelak lagi, potret kehidupan seorang juru dakwah atau dai, baik kehidupan pribadinya, maupun kehidupan keluarganya, menjadi cerminan bagi keberhasilan dakwah yang dia lakukan di tengah masyarakat. Akan dipandang tercela secara etis, bila seorang dai sibuk mendakwahi orang lain sementara keluarganya dibiarkan bergelimang begitu saja tanpa mengindahkan nilai-nilai agama yang dia serukan untuk dipegang dan diindahkan oleh orang lain. Itulah sebabnya, sebelum mengajak orang lain dan masyarakat luas, agar menerima seruan dakwah yang dia bawa, sudah sepatutnya juru dakwah memulai dakwahnya itu dari keluarganya sendiri. Penegasan seperti itu didasarkan kepada kewajiban dakwah yang dilaksanakan oleh Rasulullah SAW.

Seperti diketahui berdasarkan isyarat yang terdapat dalam al-Qur'an, sebelum tugas dakwah disampaikan oleh Rasulullah SAWkepada masyarakat luas, Allah SWT memerintahkan agar ajakan untuk menerima Islam tersebut, disampaikan oleh Rasulullah Saw. kepada kaum kerabat beliau sendiri.

Tugas risalah yang diberikan oleh Allah SWT kepada Rasulullah Saw., dimulai dari turunnya wahyu pertama di gua Hira' pada Jabal al-Nur. Wahyu pertama itu adalah surat al-'Alaq: 1-5:

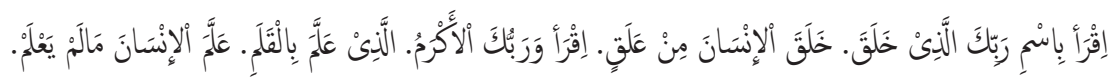

Bacalah dengan menyebut nama Tuhanmu Yang Maha Pencipta. Yang menciptakan manusia dari segumpal darah. Bacalah, dan Tuhanmu Maha Mulia. Yang mengajar dengan pena. Yang mengajar manuisa tentang apa yang mereka tidak ketahui. ( Qs. al-'Alaq 96: $1-5)$

Wahyu pertama ini menjadi dasar legitimasi tugas risalah yang akan dilaksanakan oleh Rasulullah SAW. Ini berarti, Muhammad ibn 'Abd Allah, salah seorang yatim piatu dari suku Quraisy, yang lahir di kota transit perdagangan, Mekkah, telah dipilih oleh Allah SWT menjadi utusan-Nya bagi segenap umat manusia. ia menjadi figur yang diberi peran sebagai duta dari berita langit. Ini berarti melalui lidah Muhammad ibn Abd Allah itulah, wahyu Allah, yang berisi 
ajaran-ajaran kehidupan yang bersumber dari Allah SWT tersebut, akan disampaikan.

Kemudian Allah SWT menurunkan wahyu keempat, yakni surat al-Muddatstsir ayat 1-7:

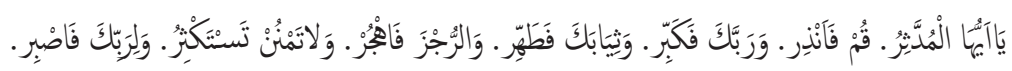

Hai orang-orang yang berselimut, bangunlah dan berilah peringatan. Dan Tuhanmu agungkanlah. Dan pakaianmu bersihkanlah. Dan perbuatan dosa tinggalkanlah. Dan janganlah kamu memberi (dengan maksud) memperoleh (balasan) yang lebih banyak. Dan untuk (memenuhi perintah) Tuhanmu, bersabarlah. ( Qs surat alMuddatstsir 74 :1-7)

Mulai saat itu kegiatan dakwahpun dilancarkan oleh Rasulullah SAW. Namun pelaksanaannya masih dalam kondisi sembunyisembunyi (dakwah sirriyah). Dakwah secara sembunyi-sembunyi tersebut dilaksanakan oleh Rasulullah SAWselama lebih kurang tiga tahun. Hal ini dilakukan karena adanya permusuhan dan penolakan keras dari pihak kafir Quraisy. Mereka memandang bahwa apa yang disampaikan oleh Rasulullah SAWmerupakan ancaman terhadap posisi mereka di mata bangsa Arab lainnya. Di samping itu segala sesuatu yang dibawah oleh Rasulullah SAWtersebut bertentangan dengan kepercayaan mereka, yakni penyembahan berhala (paganisme).

Itu sebabnya bila kaum beriman yang mula-mula ini, ingin melaksanakan shalat mereka harus melaksanakannya secara sembunyi-sembunyi. Mereka terpaksa mencari dan menelusuri celahcelah bebukitan yang jauh dari keramaian kota Mekkah. Di tempat itulah kemudian mereka beribadah melaksanakan shalat, agar tidak diketahui oleh orang lain, kaum musyrikin Mekkah. ${ }^{1}$

\section{Strategi Dakwah Rasulullah}

Selang beberapa waktu kemudian turunlah wahyu berikutnya. Wahyu tersebut berisi perintah Allah untuk menyampaikan dakwah, ajaran kepada Islam yang disampaikan secara terang-terangan, Muhammad Husein Haikal, Hayat Muhammad, Kairo, Maktabah al-Nadhah al-Mishriyyah, 1965, h. 141 
tidak lagi sembunyi-sembunyi. Penyampaian dakwah secara terangterangan ini ditujukan kepada kaum kerabat/keluarga terdekat Rasulullah Saw. Firman Allah dalam surat al-Syu'ara ayat 214:

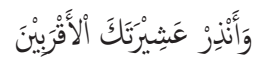

Dan berilah peringatan kepada keluargamu terdekat.(Qs. al-Syu'ara 42:214:)

Kata asyirat yang terdapat dalam ayat tersebut, menurut $\mathrm{Ibn}$ Fariz, mempunyai dua arti asal, yaitu "jumlah bilangan tertentu" dan "bergaul atau bercampur". Karena itu keluarga, kerabat, suami atau istri disebut 'asyirat', karena mereka antara satu dengan yang lain mengenal dan bergabung dalam satu rumah tangga. ${ }^{2}$ Selanjutnya menurut al-Raghib al-Ashfahani, kata tersebut mengandung arti keluarga seseorang yang merasa banyak dengan mereka, yakni mereka bagi seseorang itu menjadi berada dalam jumlah yang sempurna. ${ }^{3}$ Oleh sebab itu ayat tersebut berbicara dalam konteks perintah Tuhan kepada Nabi (termasuk umatnya) supaya memberi peringatan kepada keluarga dan kerabat yang dekat. ${ }^{4}$

Keluarga terdekat Rasulullah bila dari silsilah beliau, berawal dari Qushai. Qushai mempunyai 3 orang putra, masing-masing bernama 'Abd al-Uzza, 'Abd al-Dar dan 'Abd al-Manaf. Dari tiga putra itu, silsilah Rasulullah SAWberkaitan dengan Abd al-Manaf mempunyai 4 orang putra, masing-masing bernama Muththallib, Hasyim, Naufal dan Abd Syams. Hasyim mempunyai seorang putra bernama 'Abd alMuththallib. Selanjutnya 'Abd al-Muththallib mempunyai 10 orang putra, tetapi yang disebut nama-namanya hanya 6 orang, yakni Hamzah, Abbas, 'Abd Allah, Abu Lahab, Abu Thalib dan Harits. 'Abd Allah adalah ayah dari Rasulullah SAWsementara yang lainnya adalah paman-paman beliau.

'Abd Syam, saudara kandung kakek buyut Rasulullah SAWmempunyai keturunan secara garadual melahirkan Umayyah.

${ }^{2}$ M. Quraish Sihab, Ensiklopedi al-Qur'an Kajian Kosakata dan Tafsirnya, Jakarta, Yayasan Bimantara, edisi percobaan, 1997, h. 32

${ }^{3}$ Al-Raghib al-Asfahani, al-Mufradat fi Ghrarib al-Qur'an, Beirut, Dar al-Ma'rifah, t.th. h. 335

${ }^{4}$ M. Quraish Sihab, Ensiklopedi al-Qur'an Kajian Kosakata dan Tafsirnya, Jakarta, Yayasan Bimantara, edisi percobaan, 1997, h. 32 
Umayyah melahirkan Harb, Harb melahirkan Abu Sufyan dan Abu Sufyan melahirkan Mu'awiyah. Seperti diketahui garis keturunan ini memunculkan khalifah-khalifah Daulat Bani Umayyah'. Demikian pula, paman Rasulullah 'Abbas' juga melahirkan keturunan yang menjadi khalifah-khalifah Daulat Bani Abbas. Sementara itu silsilah Rasulullah pada lapisan pertama, yakni 'Abd al-Uzza melahirkan keturunan 'Asad dan Khuwailid. Khuwailid mempunyai 2 orang anak, masing-masing 'Awwam dan Khadijah. Siti Khadijah, sesudah bercerai dari suaminya yang pertama, kemudian menikah dengan Rasulullah SAW.

Ketika turunnya ayat tersebut, yang dimaksud dengan keluarga terdekat Rasulullah SAWadalah mereka yang hidup semasa dengan beliau. Bila disebut satu persatu mereka adalah Hamzah, Abbas, Abu Lahab, Abu Thalib dan Harits.Untuk melaksanakan perintah Allah SWT tersebut, Rasulullah SAW. pun menyeru kaum kerabatnya ini. Imam al-Bukhari meriwayatkan hal tersebut dalam Kitab Shahihnya sbb:

"Wahai putra/putri Fihr, 'Adi dan seluruh anggota suku Quraisy", sehingga mereka berkumpul, sampai yang tak dapat hadirpun mengirimkan wakilnya untuk memperhatikan apa yang disampaikan oleh Muhammad SAW, Abu Lahab dan tokoh Quraisy lainnya pun datang. Nabi Muhammad SAWbersabda: ‘Bagaimana kalau aku kabarkan kepada kalian bahwa di lembah ini ada seekor kuda yang akan menyerang kalian, apakah kalian percaya kepadaku?” Mereka menjawab: “Kami tak pernah melihat engkau berdusta", Nabi bersabda: "Sesungguhnya aku akan memperingatkan kalian tentang bahaya besar di hari kemudian". Abu Lahab berkata: "Celakalah engkau. Untuk hal inikah engakau mengumpulkan kami?" Lalu turunlah ayat Tabbat yada Abi lahab wa tabba" ( Hr Bukhari)..$^{5}$

Selanjutnya Rasulullah SAW mengundang kaum kerabat anggota keluarganya terdekat untuk makan bersama-sama di rumah beliau sendiri. Diriwayatkan, bahwa yang hadir ketika itu sampai mencapai

${ }^{5}$ Al-Bukhari, Shabih al-Bukbari, Beirut, dar al-Fikr, t.th., h. 400 
40 orang, termasuk Abu Lahab.

Setelah selesai jamuan makan, Rasulullah SAW bersiap-siap untuk memulai maksud yang akan disampaikan kepada para tamunya. Namun sebelum beliau sempat berdiri untuk maksud tersebut, Abu Lahab, memotong jalan mendahului berdiri terlebih dahulu, lalu berpidato dengan suara lantang penuh nafsu.

"Mereka (yang hadir) ini adalah saudara-saudara dan anak-anak keturunan dari saudara-saudara bapakmu. Maka (sekarang) berbicaralah! Dan hentikanlah penyelewenganmu (dari agamamu) itu. Jangan engkau menyerang agama kaummu. Jangan engkau serahkan mereka kepada kemarahan bangsa Arab, sebab sesungguhnya kaummu tidak akan sanggup melawan mereka bangsa Arab keseluruhannya. Mereka (kaummu) tidak sanggup berperang dengan mereka. ${ }^{6}$

"Kaummu sudah tahu maksudmu, hendak merubah agama mereka. Tidak tersembunyi bagi mereka apa urusanmu (yang sebenarnya) dan bahwa engkau mengajak mereka kepada penyelewengan, (mengajak mereka) supaya keluar dari tradisi nenek moyang (kita). Awaslah, jagalah keselamatan dirimu dan keselamatan keturunan bapakmu. Ketahuilah bangsa Arab tidak akan membiarkanmu (begitu saja). Tidak sukar bagi mereka untuk menyerangmu dan membunuhmu."7

"Kembalilah kepada agama bapak dan nenek moyangmu. Itulah lebih baik bagimu. Kalau tidak kami akan penjarakan engkau sampai engkau sehat kembali dari penyakitmu itu, sehingga engkau bebas dari penyakitmu. Keluargamu lebih wajar mendidikmu dan berhak untuk menangkapmu dan memenjarakanmu, bila engkau terus bertahan pada pendirianmu itu, dan itu lebih memudahkan bagimu dan bagi mereka, dari pada apabila kaum Quraisy menerkammu dengan bantuan bangsa Arab (lainnya). Aku tidak pernah melihat seseorang yang mendatangkan malapetaka kepada keluarga bapaknya seperti engkau lakukan ini."

\footnotetext{
${ }^{6}$ MohammadNatsir, Figh al-Dakwah, Jakarta, Yayasan Capita Selecta, cet X, 1996, h. 167

${ }^{7}$ MohammadNatsir, Fiqh al-Dakwah, Jakarta, Yayasan Capita Selecta, cet X, 1996, h. 167

${ }^{8}$ MohammadNatsir, Fiqh al-Dakwah, Jakarta, Yayasan Capita Selecta, cet X, 1996,h. 168
} 
Baru saja Rasulullah Saw memulai dakwah untuk keluarga terdekat, beliau sudah dihadang oleh anggota keluarga itu sendiri. Ini menunjukan setiap pendukung dakwah haruslah menyadari bahwa tantangan dakwah bisa muncul, bukan saja dari luar, tetapi juga dari dalam, yakni dari orang dekat bahkan dari kalangan keluarga sendiri.

Betapa sistematisnya argumennya yang diajukan oleh Abu Lahab dalam mematahkan maksud yang akan disamapaikan oleh Rasulullah Saw belum lagi dakwah dimulai, Abu Lahab sudah menampik keinginan Rasulullah tersebut dengan alasan-alasan yang tersusun dengan rapi. Abu Lahab memulai dengan menggambarkan posisi Muhammad sebagai seorang pesakitan yang tertangkap basah. Muhammad disebutnya sebagai al-Shab-ah (penyelewengan) dari agama nenek moyang.

Dengan memberikan predikat sebagai penyeleweng itu Abu Lahab kemudian mendesak posisi Rasulullah tersebut kepada situasi yang sangat berbahaya, bukan saja bagi diri Rasulullah sendiri, tetapi juga bagi kaum kerabatnya, yaitu keluarga Bani Hasyim. Situasi yang berbahaya itu adalah kemarahan bangsa Arab.

Dengan argumen seperti itu Abu Lahab memojokkan Nabi Muhammad sebagai orang yang telah menyeret kaum Quraisy Bani Hasyim untuk berhadapan diametral dengan bangsa Arab secara keseluruhan. Karena bukan hanya suku Quraisy tetapi juga seluruh bangsa Arab telah memeluk keyakinan terhadap berhala-hala yang ada disekeliling Ka'bah, berabad-abad yang lalu.

Oleh sebab itu dengan gaya sebagai pendukung Muhammad, Abu Lahab memperingatkan agar Muhammad menghentikan maksud tersebut. Kalau tidak, dari pada seluruh bangsa Arab akan membunuh Muhammad, lebih baik kaum kerabatnya terlebih dahulu menangkapnya dan mengobati Muhammad dari penyakit yang diidap.

Setelah berlalu beberapa hari dari undangan yang pertama, Rasulullah kemudian mengundang kaum kerabatnya yang kedua kali. Beberapa bibi beliau melarang untuk tidak mengundang Abu Lahab kembali. Namun Rasulullah tetap mengundangnya untuk datang. Demikianlah sesudah selesai makan sebelum Abu Lahab kembali bicara, seperti pada undangan sebelumnya, Rasulullah segera berdiri memulai pembicaraan. 
"Segala puji bagi Allah, aku puji Dia, aku mohon pertolongan kepadaNya, aku beriman kepada-Nya dan aku berserah diri kepada-Nya. Aku bersaksi bahwa tiada Tuhan yang layak disembah melainkan Dia satusatunya. Dan tiada sekutu bagi-Nya. Kemudian dari itu, sesungguhnya seorang al-Ra'id (perintis) tidak akan menipu keluarganya. Andai saja aku menipu semua manusia, aku tidak akan menipu keluargaku. Demi Allah, tidak ada Tuhan melainkan Dia, sesungguhnya aku ini adalah utusan Allah kepadamu khususnya dan kepada umat manusia umumnya."9

"Dan sesunguhnya Allah telah memerintahkan kepadaku, supaya aku memanggil kamu kepada-Nya, dengan firman-Nya: "Berilah peringatan kepada kaum kerabatmu yang terdekat." Aku panggil kamu kepada kalimat yang ringan di lidah, berat di timbangan, yakni penyaksian bahwa tiada Tuhan melainkan Allah, dan bahwa sesugguhnya aku adalah utusan Allah. Dan demi Allah kamu pasti mati, sebagaimna kamu tertidur, dan akan bangkit kembali sebagaimana kamu terbangun, dan pasti kamu akan dipinta tanggung jawabmu atas apa yang kamu perbuat, dan kamu akan diberi ganjaran yang baik atas amalmu yang baik, dan yang buruk atas perbuatanmu yang buruk, dan sesungguhnya (di sana) ada surga yang kekal dan ada neraka yang kekal."10

"Wahai keturunan Abd al-Muththallib. Demi Allah tidak pernah melihat seorang pemuda membawa sesuatu yang lebih tinggi nilainya dari apa yang ku bawakan kepadamu (sekarang ini). Sesungguhnya kubawakan kepadamu kebaikan dunia dan kebaikan akhirat. Maka siapakah (di antara yang hadir) yang bersedia menyambut seruanku kepada urusan (penting) ini dan bersedia mendampingiku untuk menegakkannya."11

Nabi Muhammad Saw mengawali pidatonya dengan menyebut diri sebagai seorang $R a^{\prime} i d$ (perintis), bukan sebagai seorang Shabi (penyeleweng), seperti yang dituduhkan oleh Abu Lahab dalam pertemuan sebelumnya. Seorang perintis ingin membawa kaumnya kepada keselamatan dan kesejahteraan, baik dalam kehidupan dunia maupun dalam kehidupan akhirat. Oleh sebab itu, dalam menemukan

\footnotetext{
${ }^{9}$ MohammadNatsir,Fiqh al-Dakwah, Jakarta, Yayasan Capita Selecta, cet X, 1996, h. 171

${ }^{10}$ MohammadNatsir, Fiqh al-Dakwah, Jakarta, Yayasan Capita Selecta, cet X, 1996, h. 172

${ }^{11}$ MohammadNatsir, Fiqh al-Dakwah, Jakarta, Yayasan Capita Selecta, cet X, 1996, h. 173
} 
kesejahteraan dan kedamaian hidup itu, setiap orang akan mempertanggung jawabkan perbuatannya di dunia ini. Siapa yang berbuat baik akan diberi ganjaran kebaikan, sebaliknya siapa yang bebuat jahat akan diberi ganjaran kejahatan pula. Di kehidupan nanti itu ada surga yang kekal, untuk orang-orang yang berbuat baik, dan ada neraka yang kekal untuk orang-orang yang berbuat jahat. Itulah inti dari apa yang dibawa beliau untuk kaum kerabat pada khususnya dan untuk umat manusia pada umumnya.

Mendengar ucapan Rasulullah Saw seperti itu, hadirinpun terdiam seketika. Apa yang dilontarkan oleh Abu Lahab dalam pertemuan sebelumnya mendapat informasi berimbang. Terjadi suasana pro dan kontra. Setiap orang menimbang-nimbang dalam pikirannya masingmasing, apakah menerimatuduhan Abu Lahab sebagai penyeleweng, atau mendengarkan kandungan maksud yang disampaikan oleh Muhammad Saw. yang mereka kenal selama ini mempunyai sifat alAmin (yang sangat dapat dipercaya).

Dalam suasana keheningan seperti itu, seorang pemuda belia putera pamannya, yakni Ali bin Abi Thalib, bangun dari duduknya dan dengan suara yang lantang menyatakan:

Aku ya Rasulullah!, Aku membelamu. Aku adalah musuh bagi siapa yang memusuhimu.

Suasana tersebut menjadi sangat menentukan. Terjadi situasi di mana setiap orang melihat ke arah Ali bin Abi Thalib dan ayahnya Abu Thalib. Pernyataan Ali sudah jelas, yakni akan membela agama yang dibawa oleh Nabi Muhammad dan bahkan dengan sangat lantang pula di nyatakan bahwa dia siap menjadi musuh bagi siapa saja yang memusuhi Nabi Muhammad Saw.

Dalam situasi mencekam ini Abu Thalib ibn 'Abd al-Muththallib pun berdiri pula dari duduknya dan mulai bicara.

Dan (lihatlah), itu semua kaum kerabat keturunan ayahmu, yang sedang berkumpul. Dan aku hanyalah salah seorang dari mereka. Tetapi aku tidak akan mendahului mereka untuk memenuhi apa yang kau kehendaki. 
Teruskanlah menjalankan tugasmu yang diperintahkan. Demi Allah aku akan tetap melindungimu dan membelamu. Hanya aku sendiri tidak sanggup berpisah dari agama 'Abd al-Muththallib."12

Dari ungkapan sejarah di atas, jelas terlihat betapa dakwah Rasulullah Saw terhadap kaum kerabatnya memunculkan dua kasus penting bagi kegiatan dakwah. Abu Lahab menentang keras dakwah Rasulullah, dan tidak mau memeluk agama Islam. Demikian pula Abu Thalib, mendengarkan dengan seksama dakwah Rasulullah, namun tidak mau menerima agama Islam sebagai agama. Dua paman beliau ini sama-sama tidak mau memeluk Islam, tetapi dengan motivasi yang berbda. Abu Lahab muncul sebagai musuh Rasulullah, sebaliknya Abu Thalib muncul sebagai pembela beliau.

\section{Respon Dakwah Dan Polarisasi Komunitas}

Dari gambaran di atas dapatlah disimpulkan sementara, sekurang-kurangnya ada empat kategori yang dapat dideskripsikan bagi keluarga dekat Rasulullah, dalam penerimaan mereka terhadap dakwah beliau. Pertama, mereka yang langsung menerima Islam sebagai agama dan meninggalkan tradisi nenek moyang menyembah berhala. Kedua, mereka yang menolak Islam sebagai agama dan berupaya menghalang-halangi dakwah yang dilaksanakan oleh Rasulullah. Ketiga, mereka yang juga menolak Islam sebagai agama, tetapi memberi dukungan terhadap kegiatan dakwah Rasulullah tersebut. Keempat, mereka pada awalnya tidak menerima Islam, tetapi dalam waktu agak lama kemudian baru memeluk agama Islam.

Uraian berikut akan membicarakan satu persatu anggota keluarga dekat Rasulullah Saw yang menjadi objek dakwah beliau, yakni klasifikasikan kedalam empat kategori tersebut. Kelompok pertama, mereka yang langsung menerima Islam dan meninggalkan agama nenek moyang. Orang-orang yang termasuk kepada kelompok pertama ini diwakili oleh Khadijah bint Khuwailid serta Ali bin Abi Thalib.

Siti Khadijah memeluk agama Islam pada tahun $636 \mathrm{M}$. Ia terpikat kepada kepribadian Muhammad yang di kalangan masyarakat

${ }^{12}$ MohammadNatsir, Fiqh al-Dakwah, Jakarta, Yayasan Capita Selecta, cet X, 1996, h. 174 
Mekkah dijuluki dengan al-Amin. Khadijah dikenal sebagai seorang pedagang kaya di Mekkah. Garis keturunannya bertemu dengan Rasulullah pada Qushayy. Ayahnya bernama Khuwalid, adalah cicit dari Qushay.

Sebelum memeluk agama Islam dan menikah dengan Muhammad, ia sudah menjadi janda dua kali. Pertama ia menikah dengan Abu Halal al-Nabbasy ibn Zuhrah. Dari perkawinan ini ia dianugerahi seorang anak bernama Halal. Abu Halal kemudian meninggal dunia. Siti Khadijah kemudian menikah kedua kalinya dengan Atiq ibn Abid al-Makhzumi. Suami kedua inipun meninggal dunia pula. Kembali Siti Khadijah menjadi janda. Dalam keadaan menjadi janda kedua kali ini, beberapa lamaran dari pemuka Quraisy, dia tolak.

Tidaklah secara kebetulan, bila Abu Thalib yang menjadi paman Muhammad itu, mempunyai hubungan dagang dengan Siti Khadijah. Sementara itu Muhammad sendiri tinggal di rumah pamannya itu. Untuk meringankan beban pamannya, Muhammad ikut membantu membawa dagangan ke Syam. Dengan demikian Muhammad dapat mengenal pasar dengan baik. Berkat kejujurannya, perdagangan Abu Thalib bertambah maju.

Keadaan ini diketahui oleh Siti Khadijah. Untuk memastikan dan meyakinkan dirinya tentang kepribadian Muhammad dalam perdagangan tersebut, Siti Khadijah kemudian mengutus seorang suruhannya untuk mendampingi Muhammad dalam perdagangannya itu. Selanjutnya Muhammad dipercaya pula untuk membawa dagangannya ke Syam.

Atas laporan Maisarah tentang kepribadian Muhammad inilah, Siti Khadijah kemudian memutuskan untuk meminta Muhammad sebagai suaminya. Permintaan itu ternyata mendapat sambutan. Dengan demikian berlangsunglah pernikahan antara Muhammad dan Siti Khadijah, yang ketika itu mereka masing-masing berusia 25 tahun dan 40 tahun. Dari perkawinan ini keduanya peroleh keturunan 4 puteri; Zainab, Ruqayyah, Ummu Kalsum, dan Fatimah, ketika itu ia membenarkan bahwa Muhammad mendapatkan wahyu dari Allah. Rasulullah pernah berucap ketika Siti Khadijah wafat; "Ketika aku miskin ia memberiku kekayaan dan ketika aku dianggap orang gila, ia tetap percaya kepadaku." 
Ali ibn Abi Thalib adalah orang kedua memeluk agama Islam setelah Siti Khadijah. Ia adalah sepupu Rasulullah dan kemudian menjadi menantu beliau. Ayahnya adalah 'Abd al-Muththalib ibn Hasyim ibn 'Abd Manaf. Dalam usia 6 tahun, ia sudah tinggal bersama Rasulullah, sebagaimana Rasulullah pernah tinggal bersama ayahnya. Ali berusia 8 tahun ketika Muhammad diangkat menjadi Rasul. Pembelaanya terhadap Rasulullah ia nyatakan pada jamuan makan yang dilaksanakan Rasulullah untuk kaum kerabatnya, ketika dakwah terhadap kaum kerabat pertama sekali dilakukan.

Tak pelak lagi, hubungan Rasulullah dengan Ali sangat dekat. Begitu dekatnya hubungan tersebut sehingga ia banyak menyaksikan Rasulullah SAWmenerima wahyu. Disamping itu ia juga banyak menimba ilmu berkenaan dengan keagamaan, baik teori maupun praktik. ${ }^{13}$ Ali kemudian diambil menantu oleh Rasulullah untuk putri baliau, Fatimah. Dari Fatimah, Ali dikaruniai dua orang putra Hasan dan Husen.

Kelompok kedua, mereka yang menolak dakwah Rasulullah SAWsecara terus menerus. Adapun yang masuk pada kelompok kedua ini diwakili oleh paman Rasulullah juga, yakni Abu Lahab. Nama lengkapnya 'Abd al-Uzza ibn 'Abd al-Muththalib ibn Hasyim. Ia diberi nama Abu Lahab karena mukanya agak kemerah-merahan seperti api. Dengan nama itu dimaksudkan Abu Lahab adalah (orang bermuka bagaikan gejolak api). Isterinya adalah saudara kandung Abu Sofyan ibn Fihr, yakni Ummu Jamil. Baik Abu Lahab dikenal dikalangan masyarakat Mekkah adalah orang yang kaya raya. Inilah yang menyebabkan dia menjadi takabbur dan tidak mau menerima dakwah Rasulullah SAW. ${ }^{14}$

Abu Lahab dan isterinya sama-sama menentang keras dakwah Rasulullah SAWAtas perbuatan kedua suami isteri ini, Allah menurunkan surat al-Lahab:

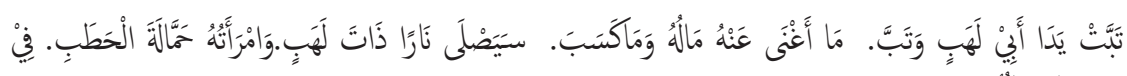

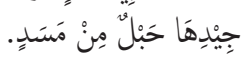

${ }^{13}$ Dasuqi, A. Hafizh, Ensiklopedi Islam, Vol. I dan II, Jakarta, Ikhtiar Baru Van Hoeve, Cet. 1,1993

${ }^{14}$ Harun Nasution, Ensiklopedi Islam Indonesia, Jakarta, Jambatan, cet 1, 1992, h. 111 
Binasalah kedua belah tangan Abu Lahab dan dia telah celaka. Tidaklah bermanfaat baginya, harta benda yang dia punyai dan juga apa-apa yang dia usahakan. Dia akan masuk kedalam neraka yang bernyala-nyala. Dan isterinya sendiri yang mengangkat kayu bakarnya. Di lehernya terikat tali dari sabut. (Qs. al-Lahab: 111: 1-5)

Kelompok ketiga, mereka yang menolak dakwah Rasulullah, tetapi membela beliau dalam situasi apapun. Kelompok ini diwakili oleh Abu Thalib ibn Abd al-Muththalib ibn Hasyim. Peranannya dalam membela dakwah Rasulullah SAWsangat besar. Posisinya sebagai salah seorang pemuka Bani Hasyim, Abu Thalib sering mendapatkan kecaman dari orang-orang suku Quraisy lainnya. Ketika terjadi pemboikotan terhadap Rasulullah dan kaum Musliman, sebenarnya hal itu tertuju juga terhadap keluarga Bani Hasyim, karena perlindungan yang mereka berikan kepada Rasulullah.

Karena posisi seperti itulah Rasulullah sangat mencintai Abu Thalib. Ketika ia dalam keadaan sakit keras dan Rasulullah mengajaknya untuk mengucapkan dua kalimat syahadat, ia tidak mau mengucapkannya dan tidak bersedia meninggalkan agama nenek moyang mereka.

Riwayat ini diuraikanoleh al-Zuhri dariSa'id ibnal-Musayyabyang menerimanya dari ayahnya al-Musayyab ibn Hazam al-Makhzumy, salah seorang sahabat Rasulullah dari kalangan Muhajirin. "Tatkala maut mendekati Abu Thalib, masuklah Nabi kedalam rumahnya dan segera ke pembaringannya. Beliau dapati Abu Jahal ibn Hasyim dan Abd Allah ibn Umayyah ibn Al-Mughirah telah duduk terlebih dahulu, lalu bersabda Nabi SAW" Wahai pamanku, ucapkanlah " $\mathrm{La}$ ilaha illa Allah, supaya paman dapat aku bela di hari kiamat di sisi Allah." Sebelum Abu Thalib menjawabnya, Abu Jahal dan Abd Allah ibn Umayyah berujar: "Hai Abu Thalib, apakah engkau tinggalkan agama ayahmu 'Abd al-Muththalib?" Tiap-tiap Rasulullah membujuk pamannya mengucapkan syahadat, setiap pula Abu Jahal dan Abd Allah ibn Umayyah mengganggu dengan menyebut agama Abd al-Muththalib, sehingga Abu Thalib menyatakan sendiri: "Biarkan aku menurut agama "Abd al-Muththalib saja". Dan dia enggan mengucapkankalimat la ilala illa Allah. ${ }^{15}$

\footnotetext{
${ }^{15}$ Imad al-Din abi al-Fida Ismail Ibn Katsir, Tafsir al-Qur'an al-Azbim, Beirut, Dar al-Fikr,
} 
Maka Allah menurunkan ayat Surat at-Taubah ayat $113^{16}$

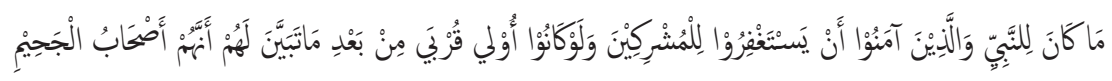

Tidak adalah bagi Nabi dan orang-orang beriman untuk memohonkan ampun bagi orang-orang musyrikin, walaupun orang-orang itu keluarga terdekat sekalipun, setelah nyata bagi mereka bahwa mereka akan menjadi penghuni neraka jahim. ( Qs.at-Taubah 9:113)

Allah menurunkan untuk Abu Lahab, ayat al-Qur' an yang terdapat dalam surat al-Qashash ayat $56^{17}$ :

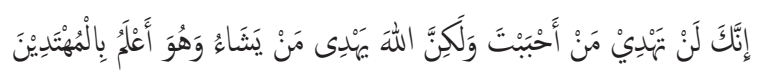

Sesungguhnya engkau tidaklah akan dapat memberi petunjuk kepada orang yang engkau kasihi, tetapi Allah-lah yang memberikan petunjuk kepada barang siapa yang Dia kehendaki, dan Dia lebih mengetahu siapakah yang dapat diberi petunjuk itu." (Qs.al-Qashash 28: 56)

Kelompokkeempat, merekayangmenerima dakwahRasulullah, tetapi dalam waktu yang cukup lama. Kelompok ini diwakili oleh Hamzah ibn 'Abd Al-Muththalib. Hamzah ibn Abd Al-Muththalib adalah paman Rasulullah juga. Usianya tidak jauh terpaut dengan Rasulullah. Oleh sebab itu, sejak kecil mereka sudah teman sepermainan. Sebagai anggota suku Quraisy, Hamzah memang tidak serta merta menerima dakwah Rasulullah Saw. tetapi kecintaannya terhadap keponakannya ini tidak dapat diganggu. Tidak pernah sekalipun Hamzah memperlihatkan ketidak sukaan terhadap Rasulullah, bahkan dia dengan segala kemampuannya melindungi Rasulullah dari gangguan siapa saja. Semakin agung nama Muhammad SAWsemakin besar

\footnotetext{
t.th., h. 136

16 Imad al-Din abi al-Fida Ismail Ibn Katsir, Tafsir al-Qur'an al-Az̧bim, Beirut, Dar al-Fikr, t.th., h. 136

${ }^{17}$ Imad al-Din abi al-Fida Ismail Ibn Katsir, Tafsir al-Qur'an al-Az̧bim, Beirut, Dar al-Fikr, t.th., h. 136
} 
kedengkian musyrikin Mekkah. Maka semakin ketat pula penjagaan Banu Muththalib terutama Hamzah terhadap Rasulullah SAW. ${ }^{18}$

Abu Sufyan juga kerabat dekat Rasulullah yang pada awal dakwah Rasulullah melakukan permusuhan terhadap beliau. Posisinya sebagai saudagar Quraisy membuat ia membenci dakwah Nabi dan melancarkan permusuhan. Ia menyuruh para penggubah sya'ir untuk menyusun sya'ir berisi penghinaan kepada nabi Muhammad Saw. sekalipun demikian, Abu Sufyan pernah secara sembunyi-sembunyi mendengarkan bacaan al-Qur'an dari nabi Muhammad yang sedang shalat malam dan mengakui daya tarik dan pesona dari al-Qur'an. ${ }^{19}$

Tetapi lama-kelamaan, setelah fathu Mekkah ia kemudian memeluk agama Islam. Betapa sangat menyentuhnya dakwah yang dilakukan oleh Rasulullah SAWterhadap Abu Sufyan ini. Di tengah situasi mencekam yang menyelimuti masyarakat Mekkah, khawatir Muhammad balas dendam, Rasulullah mengeluarkan tiga butir pengumuman penting sebagai berikut:

Barang siapa yang masuk ke rumah Abu Sufyan maka dia aman. Barang siapa yang menutup pintu rumahnya maka dia aman. Dan barang siapa yang masuk masjid maka dia aman. ${ }^{20}$

Pengumuman inilah yang membuat Abu Sufyan merasa mendapat penghormatan yang sangat tinggi. Ia ditempatkan pada posisi yang sangat terhormat. Harga dirinya sebagai pembesar Quraisy dia peroleh. Inilah sisi emosional dari dakwah Rasulullah Saw.

\section{Penutup}

Dakwah Rasulullah Saw terhadap keluarga dekatnya, tidaklah berlangsung mulus tetapi dihadapkan pada berbagai problematika. Pada waktu ajakan untuk menerima Islam dilakukan oleh Rasulullah, tidak serta merta mereka menerimanya, tetapi mereka terpecah ke dalam empat kelompok. Mereka yang menerima dakwah Rasulullah SAWdan kemudian memeluk Islam dengan meninggalkan

18 A. HafizhDasuqi, Ensiklopedi Islam, Vol. I dan II, Jakarta, Ikhtiar Baru Van Hoeve, Cet. 1, 1993, h. 77

${ }^{19}$ A. HafizhDasuqi, Ensiklopedi Islam, Vol. I dan II, Jakarta, Ikhtiar Baru Van Hoeve, Cet. 1, 1993, h. 47

${ }^{20}$ Muhammad Husein Haikal, Hayat Muhammad, Kairo, Maktabah al-Nadhah al-Mishriyyah, 1965, h. 419 
kepercayaan nenek moyang mereka, yakni menyembah berhala. Kategori ini diwakili oleh Siti Khadijah binti Khuwailid serta Ali ibn Abu Thalib.

Mereka yang menerima dakwah Rasulullah, tetapi penerimaan tersebut mengalami proses yang sangat lama. Setelah melalui peristiwa yang berliku-liku akhirnya mereka juga meninggalkan keyakinan nenek moyang menyembah berhala. Kelompok ini diwakili oleh Abu Sufyan. Mereka yang menolak dakwah Rasulullah SAWdan tetap pada keyakinan nenek moyang menyembah berhala. Di samping itu, kategori ini juga memusuhi Rasulullah dan dengan berbagai cara bermaksud mencelakakan Rasulullah Saw. kategori ini diwakili oleh Abu Lahab.

Mereka yang juga menolak dakwah RasulullahSAWdan tetap pada keyakinan nenek moyang menyembah berhala. Namun kategori ini tidak memusuhi Rasulullah, sebaliknya membela dakwah Rasulullah Saw. kategori ini diwakili oleh Abu Thalib ibn Abd Al-Muththalib serta Hamzah Ibn Abd al-Muththalib. Strategi dakwah Rasulullah yang berbasis keluarga terdekat merupakan strategi dakwah yang efektif, kerena dari dukungan keluarga terdekat inilah, beliau mendapatkan legitimasi dari masyarakat. Dengan strategi ini pula dakwah beliau membuahkan kesatuan umat: masyarakat madani yang berkeadilan, berkeadaban dan peradaban.

\section{Pustaka Acuan}

Al-Bukhari, Shahih al-Bukhari, Beirut, dar al-Fikr, t.th., h. 400

Al-Raghib al-Asfahani, al-Mufradat fi Ghrarib al-Qur'an, Beirut, Dar alMa'rifah

Dasuqi, A. Hafizh, Ensiklopedi Islam, Vol. I dan II, Jakarta, Ikhtiar Baru Van Hoeve, Cet. 1, 1993

Husein Haikal, Muhammad, Hayat Muhammad, Kairo, Maktabah alNadhah al-Mishriyyah, 1965

Imad al-Din abi al-Fida Ismail Ibn Katsir, Tafsir al-Qur'an al-Azhim, Beirut, Dar al-Fikr

Nasution,Harun, Ensiklopedi Islam Indonesia, Jakarta, Jambatan, cet 1, 1992 
366 Akhirudin

Natsir, Mohammad, Figh al-Dakwah, Jakarta, Yayasan Capita Selecta, cet X, 1996

Sihab, M. Quraish, Ensiklopedi al-Qur'an Kajian Kosakata dan Tafsirnya, Jakarta, Yayasan Bimantara, edisi percobaan, 1997 